\title{
A EMERGÊNCIA DAS INSTITUIÇÕES DE EDUCAÇÃO INFANTIL
}

\section{THE EMERGENCE OF CHILDREN EDUCATION INSTITUTIONS}

\author{
Rodrigo Saballa de CARVALHO*
}

Resumo: O presente artigo procura discutir as condições de emergência das instituições de Educação Infantil. Nesta perspectiva, tais estabelecimentos são compreendidos desde sua "entrada em cena", enquanto espaços pedagógicos, disciplinadores e educadores, implicados no "seqüestro" dos corpos, dos tempos e espaços dos indivíduos. Dessa forma, ao longo do artigo são destacadas algumas relações que se estabeleceram entre sociedade, crianças e adultos, a começar de suas atribuições, suas histórias, seus discursos e condições de existência a partir da segunda metade do século XVIII. Ressalto que as instituições de Educação Infantil enquanto maquinarias disciplinares modernas evidenciam sua positividade à medida que participam da produção de sujeitos autogovernados. Desse modo, procuro evidenciar que esses estabelecimentos foram postos em funcionamento no intuito de ordenar e regular as massas populacionais difusas, permitindo a produção de saberes sobre os indivíduos, a classificação, a diferenciação e a normalização dos mesmos.

Palavras-chave: Instituições de educação infantil. Infância. Maquinaria disciplinar.

Abstract: This article is an attempt to discuss the conditions under which children education institutions emerge. In this discussion such institutions are considered since their "first step into the scene", seen as pedagogical, disciplinary and educational spaces, involved in the "kidnapping" of the bodies, of the time and of the space of individuals. This way, throughout the article some of the relationships that developed among society, children and adults are emphasized; these relationships are discussed since their attributions, histories, discourses and existence conditions from the second half of the XVIII century on. I point out that the institutions of children education that are modern disciplinary machineries demonstrate their strength as they participate of the production of self-governed subjects. Thus, I make an attempt to demonstrate that these institutions were established in order to organize and regulate the diffuse population

\footnotetext{
* Mestre em Educação pela Universidade Federal do Rio Grande do Sul - UFRGS. Orientador pedagógico educacional no Colégio Fundação Bradesco em Gravataí/RS. rsaballa@terra.com.br
}

Olhar de professor, Ponta Grossa, 9(2): 299-316, 2006. 
allowing the production of individual knowledge, their classification, their differentiation and their normalization.

Keywords: Children education institutions. Childhood. Disciplinary machinery.

A partir das contribuições de Kuhlmann (1998; 2004), Finkelstein (1992), Varela (1992; 1994) e Cambi (1999), é possível dizer que as Instituições de Educação Infantil se configuraram enquanto estabelecimentos que serviram (ao mesmo tempo) como estratégia política, técnica e científica de disciplinamento dos indivíduos, e estiveram relacionadas com o amplo projeto de constituição da Modernidade. Dessa forma, é preciso destacar que, conforme Harvey (2000), tal projeto equivaleu a um extraordinário esforço intelectual dos pensadores iluministas no intuito de desenvolver a ciência objetiva, a moralidade, as leis universais e a arte autônoma, em busca da emancipação humana e do enriquecimento da vida diária. As promessas que se destacaram nesse período foram relativas ao domínio científico da natureza, às formas racionais de organização do pensamento e à liberação do uso arbitrário do poder, pois se acreditava que somente por meio de tal projeto poderiam as qualidades universais, imutáveis e eternas de toda humanidade serem reveladas.

É interessante observar que o domínio científico da natureza preconizava a liberdade da escassez e da arbitrariedade das catástrofes naturais, enquanto o desenvolvimento de for- mas racionais de organização social anunciava como promessa a libertação das irracionalidades do mito, da religião e da superstição. Para Cambi (1999), a Modernidade apresentou-se como uma revolução nos âmbitos geográfico, econômico, político, social, cultural e pedagógico. A partir do entrecruzamento dos âmbitos destacados, a formação do homem passou a seguir novos itinerários sociais, orientando-se conforme novos valores e estabelecendo novos modelos. Os fins da educação começaram a se destinar a um indivíduo ativo na sociedade, mundanizado, nutrido de fé laica e aberto para a "reflexão racional" de suas ações e possíveis consequiências. Os meios educativos sofreram transformações, pois a sociedade estimulou a difusão de locais formativos, como a oficina, o exército, a escola, os hospitais, as prisões, os manicômios, além da família e igreja.

Entre essas instituições, a escola passou a ocupar um lugar funcional para o desenvolvimento da sociedade moderna em relação à difusão dos princípios de ordem/produtividade e formação de profissionais das quais o sistema tinha necessidade. Pode-se dizer que as instituições dedicadas ao cuidado e educação das crianças surgiram depois das escolas e a sua en- 
trada em cena pode ser associada com o trabalho materno fora do lar, a partir da Revolução Industrial. Assim, percebe-se que a questão do trabalho materno fora do lar esteve relacionada à estrutura familiar conjugal. Conforme destaca Kuhlmann Jr. (2004), as instituições de educação infantil começaram a se delinear no continente europeu ainda no final do século XVIII com as escolas de tricotar de Oberlin, propagando-se por meio de uma circulação de pessoas e idéias pedagógicas, no intuito de atender às crianças pobres e às mães trabalhadoras. É importante ressaltar, que nesse período, a sociedade começou a estabelecer aparelhos de poder sobre a vida da população no intuito de preservar a vida dos sujeitos. Os problemas sociais passaram a ser foco de discussão e embate, pois os aspectos relacionados à população, como a repartição das epidemias, observação das condições de moradia e higiene dos sujeitos tornaram-se pauta das discussões. O aumento das populações urbanas, a crescente divisão do trabalho, a organização capitalista da acumulação e da propriedade e, posteriormente, a organização dos estados nacionais fizeram emergir formas de ver os indivíduos e as populações, caracterizando o que Foucault (1999) denomina como assunção da vida pelo poder, ou seja, a tomada do poder sobre o homem enquanto ser vivo/espécie. Esse fenômeno enunciado pelo filósofo passou a operar no sentido da constitui- ção de objetos de saber que se destinavam ao controle da própria espécie através da Demografia, Estatística, Medicina Sanitária, entre outras instâncias, que tinham como objetivo fazer viver.

Em relação à educação, é importante destacar, nesse período, o processo de laicização dos processos formativos através da escola, imprensa e vida social, destacando-se o nascimento e a difusão do livro pela expansão da alfabetização, o desenvolvimento de um novo perfil de intelectual, assim como a difusão das idéias pedagógicas. Nesse sentido, o processo de (re)orientação da educação, operacionalizou-se devido ao nascimento da Pedagogia como ciência, como saber da formação humana que se dedicava a "calcular racionalmente" as complexas (e inúmeras) variáveis, que tornavam possível o funcionamento do processo educacional.

No entanto, foi somente na segunda metade do século XIX que as instituições de educação infantil encontraram as condições de meio favoráveis para sua difusão, acompanhando o processo de expansão do ensino elementar e sendo difundidas amplamente durante as Exposições Internacionais como modelos de civilização, por serem consideradas como estabelecimentos modernos e científicos, conforme enfoca Kuhlmann Jr. (1998). As instituições européias dedicadas à educação das crianças na primeira infância localizaram-se (inicialmente) nos países em que as mu- 
lheres precisavam trabalhar para ganhar o seu sustento, corroborando com um dos principais preceitos da civilização, que era o da obrigação de ganhar a vida pelo próprio trabalho.

No Brasil, o cuidado e a educação das crianças pequenas iniciaram a partir da metade do século XX, período marcado pela urbanização, industrialização, divulgação do discurso médico-higienista, constituição de um novo estatuto familiar e criação da república. As primeiras creches brasileiras, conforme Barbosa (2000), se constituíram no intuito de atenuar a mortalidade infantil, divulgar campanhas de amamentação, atender às mães solteiras e realizar a educação moral das famílias. A difusão das instituições de educação infantil em terras brasileiras recebeu grande influência das idéias dos médicos higienistas e dos psicólogos que descreviam o que se considerava como sendo um desenvolvimento infantil normal e classificavam as condutas das crianças e de suas famílias como normais ou patológicas.

Trago tais discussões para destacar que o intuito deste artigo é o de discutir as condições de emergência das instituições de educação infantil, portanto de sua "entrada em cena" conforme se refere Foucault (2000). Nessa perspectiva, procurarei compreender tais estabelecimentos enquanto maquinarias capazes de disciplinar as subjetividades dos indivíduos para algumas formas muito particulares de viver o espaço e o tempo, a partir de categorias relacionadas com a "invenção" dos sujeitos modernos. Justifica-se, assim, o fato de que essas instituições foram (e continuam sendo) os principais estabelecimentos encarregados de construir um tipo de mundo chamado mundo moderno, cujos ideais estão sendo problematizados pela pós-modernidade.

E é justamente a partir de todos estes ditos que discutirei como as instituições de educação infantil se constituíram e se difundiram na sociedade enquanto instituições implicadas no disciplinamento através do controle dos corpos, tempos e espaços dos indivíduos. Dessa forma, ouso dizer que procurarei fazer a crítica conforme nos ensina Foucault (1981), tornando difíceis os gestos fáceis demais, ou seja, problematizando sobre que tipo de evidências, de familiaridades, de modos de pensamento adquiridos e não refletidos repousam as práticas que estiveram associadas às mudanças econômicas, políticas e sociais que ocorreram na sociedade.

\section{CONSTITUINDO (NOVOS) MO- DOS DE PODER-SABER SOBRE A INFÂNCIA}

A ocorrência de uma série de fenômenos políticos, econômicos e demográficos, marcou o início dos tempos modernos no Ocidente. Tais fenômenos fizeram surgir (na segunda metade do século XVIII) uma biopolítica da população, que é descrita por Foucault (1988, p. 131) como 
sendo: "um conjunto de processos [envolvendo] a proporção dos nascimentos e dos óbitos, a taxa de reprodução, a fecundidade de uma população" entre outros fatores. Dessa forma, é possível dizer que essa tecnologia de poder fez com que a vida e seus mecanismos entrassem no domínio dos cálculos explícitos, fazendo do poder-saber um agente de transformação da vida humana. Tal poder sobre a vida dos indivíduos é descrito pelo referido autor (1999, p. 296) como sendo

cada vez menos o direito de fazer morrer e cada vez mais o direito de intervir para fazer viver, e na maneira de viver, e no "como" da vida, a partir do momento em que, portanto, o poder intervém sobretudo nesse nível para aumentar a vida, para controlar seus acidentes, suas eventualidades, suas deficiências, daí por diante a morte, como termo da vida, é evidentemente o termo, o limite, a extremidade do poder.

Nesse sentido, é importante ressaltar que tal biopolítica se desenvolveu em relação a dois pólos complementares. O primeiro centrou-se no corpo-máquina, através de seu adestramento, na ampliação de suas aptidões, na extorsão de suas forças, a partir da disciplina difundida pelas instituições. Já o segundo centrouse no corpo-espécie através de uma série de intervenções e controles reguladores, que possibilitaram estimar a natalidade e a mortalidade, o nível de saúde, a duração da vida, a longevidade, entre outras operações. Sendo assim, as disciplinas do corpo e as regulações da população passaram a constituir os dois pólos em torno dos quais se desenvolveu a organização do poder sobre a vida.

A articulação entre os pólos indivíduo e espécie pode ser destacada através da influência médica que foi exercida na divulgação de uma política natalista contraceptiva desenvolvida em relação às mulheres. Tal prática é explicada por Foucault (1979, p. 275) quando afirma que "praticava-se a contracepção não para que as crianças não nascessem, mas para que as crianças pudessem viver, uma vez nascidas".

Pode-se dizer, portanto, que, no século XVIII, o discurso sobre nascimentos passou a incorporar a idéia de contracepção, pois, nessa época, mais crianças morriam do que sobreviviam à primeira infância. A contracepção se mostrou como uma forma de impedir o nascimento de crianças no intuito de preservar a vida das já nascidas. Iniciou-se, então, a contabilização da alta taxa de mortalidade infantil e o exercício de controle sobre o cuidado dispensado pelas amas-deleite, porém essa medida tornou-se pouco produtiva devido à grande distância que muitas delas se encontravam dos centros urbanos. A partir desse momento, os discursos médicos e higiênicos impuseram às mães o amor e o cuidado em relação aos seus filhos. De acordo com Dornelles 
(2002), o combate ao trabalho das amas-de-leite e serviçais, possibilitou novas formas de ver as tarefas educativas e uma reorganização dos comportamentos considerados educativos. Esse movimento trouxe consigo a difusão da medicina doméstica, ou seja, um conjunto de conhecimentos e de técnicas que permitiu às classes burguesas tirarem seus filhos da influência "negativa" das serviçais. Por outro lado, tal campanha pela amamentação procurava, também, diminuir os custos sociais com a manutenção de entidades destinadas aos menores abandonados, assim como controlar a reprodução dos mais pobres.

Nessa perspectiva, Yalom (1988) afirma que, no referido século, houve por toda Europa um violento protesto contra as amas-de-leite a partir das fileiras de moralistas, filósofos médicos e cientistas que tinham como intuito provar que o que era natural para o corpo humano era basicamente bom para o organismo político. É interessante observar que a saúde física era considerada uma metáfora da saúde do estado, e os seios representavam a doença ou o bem-estar. Dessa forma, os discursos circulantes que enunciavam a defesa da amamentação pelas mães (uma forma de controlar o corpo feminino), classificavam os seios entre "corruptos" (referentes às amas-de-leite) e "maternais" (associados à regeneração familiar e social). Sendo assim, difunde-se, conforme Uberti (2002), a lei do cuidado como uma das principais leis morais no âmbito familiar. A família torna-se o lugar no qual se inscrevem determinadas formas de transmissão de valores, pois seu intuito é o de favorecer o período da infância. Tais relações ocorrem em forma de obrigações como a amamentação das crianças pelas mães, a preocupação com um vestuário sadio, exercícios físicos para o um bom desenvolvimento do organismo, etc. Nesse sentido, Foucault (1979) afirma que a família, a partir de então, adquire uma figura material, pois se organiza como o espaço mais próximo da criança, no qual ela encontra condições de sobrevivência e desenvolvimento.

A partir de todas as discussões apontadas, penso ser possível compreender a "campanha" pelo aleitamento (no século XVIII) enquanto uma estratégia biopolítica. Tal estratégia pode ser relacionada a um investimento no corpo da nação, pois se investe (e se regula) o corpo individual (da mãe e do lactante) para que o corpo social seja incrementado. Através de seus mecanismos de controle e governo da população, foram estabelecidos aparelhos de poder, no intuito de preservar a vida dos indivíduos. Dessa forma, a noção de população como um corpo múltiplo (necessariamente numerável) possibilitou objetivar um campo de intervenção que se introduziu no pensamento político com um papel organizacional eficaz, pois, para governá-la, foi preciso (antes de tudo) conhecê-la. As 
estatísticas, os métodos, os cálculos, as estimativas, difundiram-se como meios de conhecer e governar a ascendente população.

Em função da crescente preocupação com o fator populacional, a criança tornou-se objeto de investigação, investimento e preservação, especialmente com a sua procriação e sexualidade. A necessidade de assegurar a preservação e utilidade dos indivíduos tornou necessária a preocupação com a saúde da população em geral e das crianças em específico. Nesse sentido, Foucault (1979, p. 199) afirma que:

ao problema "das crianças"(quer dizer, de seu número no nascimento e da relação da natalidade-mortalidade) se acrescenta o da "infância" (isto é, da sobrevivência até a idade adulta, das condições físicas e econômicas dessa sobrevivência, dos investimentos necessários e suficientes para que esse período de desenvolvimento se torne útil, em suma, da organização dessa "fase" que é entendida como específica e finalizada). Não se trata, apenas, de produzir um maior número de crianças, mas de gerir convenientemente essa época da vida.

Através deste investimento na vida, é possível dizer que a infância tornou-se um problema, pois, além da necessidade de manter a sobrevivência das crianças, foi necessário que esse período se tornasse útil. Assim, iniciou-se um processo de intervenção na reprodução dos indivíduos, nos nascimentos e na condução de vida dos nascidos, através da propagação de discursos que visavam ao investimento e ao controle da infância. Nesse sentido, é importante destacar o dito por Foucault (1988) ao afirmar que o poder de verdade desses discursos fez com que a criança passasse a ser vigiada por toda uma ronda de babás, serviçais, pedagogos e médicos, fazendo do infantil um foco local de poder-saber, que veiculava formas de sujeição e esquemas de conhecimentos, numa espécie de vaivém incessante. Concordo com o autor e saliento que médicos, pedagogos e professores começaram a dirigir conselhos às famílias e autoridades, prescrevendo a conduta infantil a partir da vigilância. É possível dizer que, a partir de então, houve um processo de produção e circulação de uma variada literatura de preceitos e advertências em relação à educação das crianças. Nesse sentido, é importante destacar que um dos efeitos da produção da referida literatura foi a difusão de diferentes discursos a respeito da conduta infantil que estavam imersos em uma gama de relações de poder.

Sendo assim, acompanho Dornelles (2002) quando afirma que a emergência da criança como acontecimento visível fez com que essa passasse a ser dita, explicada, caracterizada como um ser inocente, diferente 
do adulto, que precisava de cuidado, proteção e disciplinamento. É importante observar que tais medidas em relação à criança, passaram a ser exercidas na família e nos colégios, com um controle de cunho cada vez mais rígido e total.

Nessa perspectiva, é interessante observar, a partir da pesquisa realizada por Souza (2000), que o século XVIII acentuou a imposição de regras de comportamento, sendo que a Igreja e o Estado assumiram a responsabilidade pelo sistema educativo, tornando o processo de escolarização mais evidente. Sendo assim, as famílias foram incentivadas a colocarem suas crianças no espaço escolar, ao mesmo tempo em que se foram delineando políticas de proteção à infância na Europa. Pode-se dizer, portanto, que as novas formas de perceber as famílias e a sociedade passaram a atuar como propulsoras das instituições educacionais modernas, das quais podem ser destacados os estabelecimentos dedicados ao atendimento às crianças.

A partir dos mecanismos de regulação da população, foram-se configurando condições de possibilidade que tornaram possível o nascimento da escola nacional, dentre as quais se destacaram:

1. a definição de um estatuto de infância; 2. a emergência de um espaço específico destinado à educação das crianças; 3. o aparecimento de um corpo de especialistas da infância dotados de tecnologias específicas e de "elaborados" códigos teóricos; 4 . a destruição de outros modos de educação; 5. a institucionalização propriamente dita da escola. (VARELA, 1992, p. 69).

Tais condições, que possibilitaram o aparecimento da escola nacional e do pensamento pedagógico moderno, estiveram, de certa forma, relacionadas à emergência e difusão das instituições de educação infantil. A partir da primeira metade do século XIX, na Europa, as crianças abandonadas, que no século anterior eram recolhidas juntamente com as populações desviantes nas prisões, hospícios e asilos de mendicidade, passaram a ser atendidas em locais específicos, pois começou a existir uma diferenciação em relação aos estabelecimentos assistenciais. Através da busca pela diferenciação do atendimento à infância, foram criados os berçários, as casas-asilo, os lactários, os consultórios de puericultura e as salas de custódia para atender às crianças pequenas.

Esses estabelecimentos nasciam a partir de um novo sentimento em relação à infância e ao respectivo cuidado que deveria ser dispensado a essa etapa da vida, sendo que foram apresentados em oposição aos locais que recebiam crianças abandonadas, com a intenção de que as mães mantivessem a guarda de seus filhos contando com o cuidado e assistência. Justifica-se, assim, a estruturação das instituições dedicadas às crianças, a 
partir de uma gama de diferentes denominações, buscando viabilizar o atendimento do respectivo contexto social no qual elas estavam situadas.

Nesse período, grande parte dos sistemas de educação nacional organizaram-se nos países europeus, utilizando-se de fundamentação pedagógica, materiais e métodos para o trabalho com as crianças. Tal difusão da educação foi considerada como um dos critérios para medidas de desenvolvimento dos países. As instituições de educação infantil, segundo Barbosa (2000), apesar de não fazerem parte dos sistemas educacionais, foram consideradas como elementos importantes de uma concepção cultural que definia que as crianças poderiam ser cuidadas em um ambiente extrafamiliar.

Nesse sentido, Kuhlmann Jr. (1998) afirma que tal difusão das instituições de educação infantil esteve pautada em uma nova concepção assistencial e científica, pois havia uma proposta de progresso da ciência, que legitimava as práticas emergentes relacionadas ao atendimento institucional das crianças na primeira infância. A partir das considerações do referido autor, é possível destacar que as creches "nascidas" na Europa foram consideradas como "solução" para os cuidados da infância, em função da necessidade do trabalho feminino no processo de industrialização. Carl Kaestle e Maris Vinosvskis (apud FINKELSTEIN, 1992, p. 190) corroboram com tais informações ao enfa- tizarem que os discursos circulantes na época do surgimento das instituições de educação infantil européias argumentavam que elas estavam vinculadas à idéia de melhorar a qualidade do ambiente dos/das filhos/as trabalhadores/as fabris. É possível dizer que, nesse sentido, havia uma concepção de que a família seria, de certa forma, "incapaz" de administrar a educação de sua prole.

Pode-se dizer, portanto, que esses locais de educação e cuidado das crianças foram se constituindo a partir de embates políticos, econômicos e sociais situados no quadro das mudanças civilizadoras, que definiam uma visão moderna de sujeito. Assim, tais mudanças estiveram pautadas na individualização dos sujeitos, no controle das emoções, no desenvolvimento da autoconsciência e no estabelecimento de um código de conduta partilhado, impulsionados pelas nascentes configurações de sociedade e família.

Conforme Barbosa (2000), nesse processo de difusão das instituições dedicadas ao atendimento da primeira infância, as práticas de educação e cuidado das crianças foram deslocadas de ações moldadas por grupos familiares, privados para sistemas modernos, públicos e globais, evidenciando uma preocupação com a ascendente população infantil. Sendo assim, várias experiências marcaram as iniciativas de atendimento educativo às crianças, tais como as creches, as salas de asilo francesas, as esco- 
las de jogo, os Jardins de Infância froebelianos, as Casas dei Bambini de Maria Montessori e as escolas maternais. Desse modo, tais espaços se constituíram com intuito disciplinar as crianças e suas famílias, de acordo com as necessidades de formação do que se acreditava como ideal de homem e sociedade moderna. Dessa forma, é preciso levar em consideração que tais pressupostos influenciaram outros países, como o Brasil, por meio da circulação de discursos de proteção e assistência à infância. Nesse sentido, discutirei na próxima seção o estabelecimento e expansão das instituições de educação infantil no Brasil.

\section{DISCIPLINANDO CORPOS E "CIVILIZANDO"MENTES}

Os pressupostos de formação do homem moderno, difundidos na Europa, repercutiram em terras brasileiras. Dessa forma, a educação das crianças em nosso país também passou a ser um campo de regulação, controle e conseqüente intervenção social, sendo justificada pela influência da classe média nos movimentos de assistência à infância. Desse modo, as primeiras propostas de instituições de Educação Infantil no Brasil, conforme Kuhlmann Jr. (1998), ocorreram a partir da fundação do Instituto de Proteção e Assistência à Infância (IPAI-RJ) e da inauguração da Creche da Companhia de Fiação e tecidos do Corcovado (a primeira creche brasileira), ambas as ações desenvolvidas em 1899. Dessa forma, é possível dizer que as primeiras creches brasileiras foram criadas tendo como intuito a redução da mortalidade infantil, a divulgação de campanhas de amamentação e o atendimento às mães solteiras para realização de uma educação moral das famílias.

Nesse processo, os estabelecimentos dedicados à educação infantil, começaram a ser reconhecidos como sinônimo de progresso e difundiram-se a partir dos movimentos de urbanização, industrialização, divulgação do discurso médico-higienista, (re)organização da família e criação da república. Propagou-se uma série de discursos (médicos, pedagógicos, psicológicos, políticos e jurídicos), que defendiam a educação infantil como sendo necessária à formação de (futuros/as) cidadãos/ãs "corretos/ as" e disciplinados/as. Sendo assim, as instituições de educação infantil passaram a ter uma importante função na operacionalização de uma nova forma de exercício do poder, não mais centrada em punições e castigos físicos (conforme modelo pedagógico corretivo), mas na normalização das condutas das crianças e de suas famílias.

É importante salientar que, em relação aos discursos da saúde, as instituições de educação infantil (assim como as escolas regulares) foram vistas pelos médicos e sanitaristas enquanto espaços através dos quais seria possível realizar um trabalho com 
as crianças e suas famílias, principalmente no que se referia aos aspectos higiênicos e físicos. Pode-se dizer, portanto, que a pedagogia higiênica tinha interesse (especial) pelas crianças, pois considerava que o trabalho com os pequenos era um passo importante na "produção" do adulto adequado à ordem médica.

Nesse sentido, a preocupação com a saúde e bem-estar das crianças, conforme Souza (2000, p. 6), levava a família a operar como "uma máquina voluntária e responsável pela criação e moralização das crianças, na qual os adultos se comprometeriam com a tarefa de promover o bem-estar físico e mental de sua prole", em aliança com os pressupostos médicos. Levando em consideração os aspectos discutidos em relação ao interesse (dos médicos), é possível fazer uma aproximação com o dito por Foucault (1979), quando afirma que a família (a partir do final do século XVIII) deixa de ser uma teia de relações que se inscreve em um estatuto social e tornase um meio físico denso, saturado, contínuo, permanente, que mantém e favorece o corpo da criança. Nesse sentido, é possível observar que os médicos higienistas e os sanitaristas perceberam a potencialidade das famílias para o desenvolvimento de uma consciência sanitária na população, utilizando-se da educação das crianças como estratégia de aproximação dos lares. Por outro lado, é preciso levar em consideração que esta influência higienista na educação das cri- anças, também evidenciou a preocupação da Medicina em relação à mortalidade infantil, cujas propostas se integravam ao projeto geral de saneamento que pretendia desenvolver a civilidade das pessoas e a modernidade do país.

Destacaram-se, dessa forma, especialmente os movimentos de assistência à infância, relacionados à implantação de creches e iniciativas associadas à proteção à maternidade, que visavam à "produção" de mães que almejassem a constituição de lares higiênicos e a criação de filhos saudáveis. No entanto, é necessário dizer que tais instituições definiram metas vinculadas à saúde, porque as crianças (assim como os imigrantes e as etnias consideradas "inferiores") eram vistas como alvos principais da higiene. Justificava-se, assim, a ação das práticas higiênicas em relação às crianças e suas famílias, pois, dessa forma, a medicina estaria contribuindo para o saneamento da população menos abastada. Tais práticas representaram (naquele período histórico) uma alternativa importante para implementação da educação de hábitos nas crianças e de suas famílias através das instituições educacionais, que visavam ao estabelecimento de um minucioso controle e "mudança" dos costumes mais simples e rotineiros.

Nesse sentido, retomo as palavras de Foucault (1999) quando afirma que a Medicina tem efeitos disciplinares e regulamentadores, pois incide ao mesmo tempo sobre o corpo e sobre as 
populações, sobre os organismos e sobre os processos biológicos. Em relação às instituições de educação infantil, os referidos efeitos podem ser percebidos no lugar de destaque que esses espaços ocuparam na divulgação de uma mentalidade higiênica com vistas ao desenvolvimento de bons hábitos nas famílias, crianças e comunidade.

Conforme destaquei no início do artigo, os discursos médicos afirmavam que era preciso criar não apenas maternidades, mas também muitas creches e escolas como objetivo de reduzir a mortalidade infantil. Essas medidas estavam relacionadas à ascensão dos ideais burgueses, que visavam a alterar o perfil sanitário da família a partir da "apropriação" dos costumes europeus e da urbanização dos hábitos. Desse modo, as instituições de educação infantil serviram como estratégia de consolidação de um discurso científico aplicado à educação, no qual se operacionalizava uma pedagogia científica respaldada pelos discursos de racionalidade e ordem.

Em relação à "produção" dos discursos pedagógicos e psicológicos, Varela (1996) destaca que as instituições de educação infantil se converteram em "verdadeiros laboratórios", nos quais se obtiveram saberes e se ensaiaram formas de trabalhar com as crianças. Nessa perspectiva, as contribuições da Psicologia (experimental e genética) foram sendo incorporadas pelos/as pesquisadores/as, que, assim passaram a contribuir com a produção de saberes relacionado a uma "nova" concepção de infância. Tais discursos fortaleceram, através da Pedagogia, os anseios das classes emergentes, que almejavam o título de modernas. Sendo assim, essa vontade de saber e de poder da Pedagogia, em medir, vasculhar, esquadrinhar, passou a ser incorporada como medida constante na instalação das instituições de educação infantil.

É possível destacar que se estava constituindo uma (nova) configuração social no nosso país, evidenciando uma ascendente preocupação em atender às emergentes demandas da sociedade, a partir do ideal positivista de "ordem e progresso". Tal ideal destacou-se através dos discursos políticos republicanos, que defendiam o desenvolvimento científico e tecnológico como a "solução" para os problemas sociais. Nessa perspectiva, é importante salientar que, segundo Souza (2000, p. 71):

no Brasil a implantação dos Jardins de Infância, ocorrida no final do século XIX, suscitou inúmeras resistências, apesar de alguns esforços feitos no sentido de convencer educadores, políticos e famílias de sua importância enquanto instituições educacionais modernas. Dentre os discursos produzidos no sentido de defender a implantação dos Jardins, destacase o Parecer ao Projeto da Reforma do Ensino Primário de 1882, elaborado por Ruy Barbosa. 
As resistências apontadas pela autora em relação à implantação dos Jardins de Infância em nosso país se devem, entre outros fatores, aos modos de como se entendia a educação das crianças (desde os fins do período imperial), pois tais estabelecimentos eram concebidos a partir de uma visão filantrópica, religiosa e assistencialista. Nos referidos discursos políticos, que defenderam a difusão das instituições de educação infantil, houve uma ênfase em relação ao atendimento educativo que deveria ser prestado às crianças, como forma de promoção da "civilidade" e de saneamento das condições de vida das populações pobres. Nesta campanha educacional difundida pelos referidos discursos, destacaram-se os eixos saúde, moral e trabalho, através dos quais deveria ser desenvolvida a educação do povo. Assim, enfatizo que esses eixos destacados pela autora em relação à promoção da educação estiveram primeiramente direcionados à família nuclear burguesa, sendo expandidos em relação às classes populares posteriormente.

Conforme salientei anteriormente a respeito da influência médico-higienista na difusão da educação infantil, assim como na normalização dos hábitos das crianças e de suas respectivas famílias, considero relevante retomar tal discussão e destacar que, no século $\mathrm{XX}$, a escola continuou sendo chamada a oferecer a sua colaboração na divulgação de campanhas de saúde e no desenvolvimento de programas de higiene. Pode-se dizer, portanto, que a educação sanitária continuava sendo vista (ainda com maior ênfase) como estratégia através da qual se poderia desenvolver um sistema de hábitos, cujo alvo prioritário era a infância. Nesse sentido, educação e saúde passaram a ser considerados como elementos indissociáveis de um programa de moralização, cujo principal pressuposto consistia na higienização da população. A partir da pesquisa desenvolvida por Rocha (2003b, p. 40), é possível salientar que, no referido século, acentuaram-se as preocupações com as questões relativas à higiene, sendo que os objetivos de tal proposta eram de

eliminar atitudes viciosas e inculcar hábitos salutares, desde a mais tenra infância. Criar um sistema fundamental de hábitos higiênicos, capaz de dominar, inconscientemente, toda a existência das crianças. Modelar, enfim, a natureza infantil, pela aquisição de hábitos que resguardassem a infância da debilidade e das moléstias.

À medida que os referidos objetivos foram sendo divulgados, houve a necessidade de elaboração de programas para o ensino da higiene nas escolas, tendo em vista o desenvolvimento da consciência sanitária nas crianças e o respectivo alcance dos propósitos almejados. Sendo assim, a educação das crianças passou a ser orientada por um programa cujos princípios “correspondiam” ao (suposto) 
caminho que elas "deveriam" percorrer na aquisição dos hábitos higiênicos. Esse caminho, conforme os médicos-higienistas, era composto por quatro etapas, que consistiam em imitação, obediência, amor-próprio e raciocínio.

A partir das discussões desenvolvidas a respeito da expansão das instituições de educação infantil e de suas metas relacionadas à saúde, considero possível compreender tais ações enquanto estratégia biopolítica, pois se evidencia uma preocupação com a população como um problema a um só tempo científico e político, com vistas à preservação da vida.

Dessa forma, considero relevante retomar o conceito de biopolítica, a partir de Foucault (1997, p. 89), como:

a maneira pela qual se tentou racionalizar os problemas propostos à prática governamental, pelos fenômenos próprios de um conjunto de seres vivos constituídos em população: saúde, higiene, natalidade, raças, etc. Sabe-se o lugar crescente que esses problemas ocuparam, desde o século XVIII, e as questões políticas em que eles se constituíram até os dias de hoje.

Sendo assim, é interessante observar que, desde o final do século XVIII, a Medicina passou a ter como uma de suas (principais) atribuições a higiene pública, através da coordenação dos tratamentos médicos, centralização das informações e normalização do saber, operacionalizando o desenvolvimento de campanhas de aprendizado da higiene e de medicalização da população.

Torna-se imprescindível enfatizar que nessa difusão da educação infantil, além do higienismo, também foram significativas as influências jurídicopolicial e religiosa como articuladoras do processo de legitimação da necessidade de criação dos estabelecimentos específicos para o atendimento às crianças. É Kuhlmann Jr. (1988) quem destaca em suas pesquisas que, em relação ao ponto de vista jurídicopolicial, foram as preocupações com as legislações trabalhista e criminal que trouxeram como pauta de discussão a preocupação com a infância moralmente abandonada, sendo estabelecida a fundação do Patronato de Menores. Por outro lado, para o referido autor, a influência religiosa também obteve destaque nesse processo de difusão das instituições de educação infantil, pois, seguindo o exemplo de outros setores, foram realizados congressos católicos tendo em vista a organização do clero e dos leigos militantes para a implementação de políticas assistenciais. Nesse aspecto, destaco que havia a orientação da criação de creches junto às indústrias, sendo que o intuito da operacionalização de tal recomendação consistia na regulamentação do trabalho feminino fora do âmbito familiar.

As considerações abordadas no decorrer da seção permitem perceber que as instituições de educação infantil tiveram sua difusão em nosso 
país, devido às (emergentes) concepções de infância, ao papel social das crianças e à possibilidade de tornálas "produtivas" e disciplinadas, através da educação. Justifica-se, assim, o dito por Souza (2000) quando afirma que as instituições de educação infantil foram acionadas (desde a sua criação) como aparatos de controle, que tinham como intuito a formação de crianças educadas para a obediência, disciplinadas e cumpridoras dos seus deveres. Sendo assim, o processo de implantação das instituições conviveu com argumentos que legitimaram a produção de saberes sobre as crianças, através do olhar dos adultos, com seus diferentes objetivos e propostas, que, a partir de certo momento, começaram a ser divulgados na legislação como forma de conquistar espaço para instalação de um número crescente de instituições dedicadas à educação das crianças. Conforme Souza (2000, p. 79), no Brasil, o discurso oficial principalmente a partir de 1940, passou a defender a

expansão dos Jardins como importantes instrumentos de governo das crianças e de suas famílias. O decreto-lei número 90, de 15/08/ 42 estabelecia como objetivos do Jardim de Infância proporcionar à criança condições que pudessem favorecer o desenvolvimento integral, preencher deficiências da educação dada no lar, prepará-la para a aprendizagem escolar, iniciá-la na vida social proporcionando-lhes situações e recursos para a aquisição de hábitos e atitudes de vida social, mas especificamente construindo hábitos mentais, morais, sociais, cívicos, higiênicos e estéticos conforme Boletim do CPOE/RS (1950, p. 35).

As contribuições da autora permitem salientar o caráter disciplinar da educação infantil e a sua produtividade em relação à "formação" de indivíduos em consonância com as expectativas sociais do referido período. É possível dizer, portanto, que tais instituições se estruturaram no Brasil (assim como em vários países ocidentais) com diferentes denominações e prestações de serviços de cuidado e educação diversificados, procurando atender às demandas sociais do contexto no qual estavam inseridas. Por outro lado, é possível dizer que, a partir da década de 50 do século XX, houve propostas de consolidação das propostas de implementação e expansão das instituições de educação infantil (Jardins de Infância), pois, em diferentes locais do país, começaram a surgir novas turmas, assim como publicações a respeito da instalação e funcionamento de tais estabelecimentos. Dessa forma, percebe-se que as instituições de educação infantil passaram a fazer pauta das discussões a respeito da oferta de cuidado e educação para as crianças na primeira infância.

Sendo assim, considero importante destacar que não prosseguirei a discussão a respeito da expansão das instituições de educação infantil (e de 
suas problemáticas) até os dias atuais. Justifico essa escolha retomando o objetivo do artigo, que é o de evidenciar e problematizar (algumas) condições de emergência desses estabelecimentos, para (na medida do possível) compreender algumas estratégias de exercício do poder disciplinar, assim como seus efeitos. Passo, então, a destacar, na próxima seção, (algumas) considerações para pensar a escola infantil enquanto "maquinaria" disciplinar.

\section{CONSIDERAÇÕES PARA PEN- SAR AS INSTITUIÇÕES DE EDU- CAÇÃOINFANTIL}

Através de incursões na história da educação, procurei enfocar algumas condições de emergência das instituições de educação infantil e suas respectivas relações com o amplo projeto de constituição da Modernidade. Dessa forma, retomo as discussões desenvolvidas no decorrer do artigo e saliento que tais espaços educativos foram pensados como instituições que se estabeleceram e se desenvolveram relacionadas com as práticas sociais, culturais, religiosas e econômicas, que se produziram na sociedade moderna. Justificam-se, dessa forma, as contribuições de Kuhlmann Jr. (1998) quando afirma que, embora exista uma diversidade de opiniões sobre as causas e temas que influenciaram a constituição das instituições de educação infantil, destacam-se a articulação dos interesses jurídicos, empresariais, políticos, médicos, pedagógicos e religiosos enquanto uma composição de forças que possibilitou a difusão de tais estabelecimentos. Nessa perspectiva, é importante destacar que participaram como elementos da referida composição a infância a maternidade e o trabalho feminino fora do lar, enquanto aspectos presentes na história das instituições.

Trago tais discussões com a intenção de apontar para o fato de que, conforme Veiga-Neto (2003), o elo entre a escola e a sociedade moderna é a disciplinaridade (no que se refere tanto à disciplina-corpo quanto à disciplina-saber). Embora o autor esteja se referindo à escola regular, penso ser possível realizar uma aproximação de tal contribuição em relação às instituições de educação infantil. À medida que as instituições de educação infantil se expandiram paralelamente ao processo de escolarização (de massas), receberam influências das escolas regulares e também estiveram implicadas na operacionalização do poder disciplinar - que teve (e tem) como intuito o desenvolvimento da "capacidade" dos indivíduos se autogovernarem.

Sendo assim, é possível dizer que as instituições de educação infantil operaram (e continuam operando) através de suas diferentes práticas escolares na produção de subjetividades, "ensinando" aos indivíduos formas de ser e se relacionar com o mundo no qual estão inseridos. Justi- 
fica-se, dessa forma, o dito por VeigaNeto (2003), quando afirma que a escola (incluo também as escolas infantis) "funcionou e continua funcionando como uma fábrica que fabricou e continua fabricando novas formas de vida". Nesse sentido, é preciso levar em consideração que muitas das práticas que são desenvolvidas nessas instituições não têm somente o objetivo de que as crianças aprendam melhor, mas também o de que sejam "produzidos" (novos) sujeitos.

Desse modo, penso ser possível dizer que os ditos que auxiliaram na organização da trama do presente artigo podem-nos ajudar a pensar e a problematizar as instituições de educação infantil desde a sua "entrada em cena", como estabelecimentos disciplinares que possuem uma relação imanente com a sociedade da qual fazem parte.

\section{REFERÊNCIAS}

BARBOSA, M. C. S. Por amor e por força: rotinas na educação infantil. Tese (Doutorado em Educação) - Universidade Estadual de Campinas, Campinas, 2000.

CAMBI, F. A modernidade como revolução pedagógica. In: História da pedagogia. São Paulo: UNESP, 1999.

DORNELLES, L. V. Meninas no papel. Tese (Doutorado em Educação) - Universidade Federal do Rio Grande do Sul, Porto Alegre, 2002.

FINKELSTEIN, B. Incorporando as crianças à história da educação. Teoria \& Educação, Porto Alegre, n. 6, p.183-220, jan./jul. 1992.

FOUCAULT, M. Microfísica do poder. Traduzido por Roberto Machado. Rio de Janeiro: Graal, 1979.

Então, é importante pensar? Libération, n. 15, p. 21, maio 1981. Disponível em: < http://www.unb/fe/tef/ filoesco/foucault/importantepensar.hml >. Acesso em: 19 jul. 2004.

O dispositivo da sexualidade. In: FOUCAULT, M. História da sexualidade I: a vontade de saber. Rio de Janeiro: Graal, 1988.

Nascimento da biopolítica. In: FOUCAULT, M. Resumo dos cursos do Collège de France (1970-1982). Rio de Janeiro: Jorge Zahar, 1997.

. Aula do dia 17 de março de 1976. In: FOUCAULT, M. Em defesa da sociedade. São Paulo: Martins Fontes, 1999.

HARVEY, D. Passagem da modernidade à pós-modernidade na cultura contemporânea. In: . A condição pós-moderna: uma pesquisa sobre as origens da mudança cultural. São Paulo: Loyola, 2000.

KUHLMANN, M. J. As exposições internacionais e a difusão das creches e jardins-de-infância. In: _ Infância e educação infantil: uma abordagem histórica. Porto Alegre: Mediação, 1998.

Instituições pré-escolares assistencialistas no Brasil (1899-1922). In: KUHLMANN, M. J. Infância e educação infantil: uma abordagem histórica. Porto Alegre: Mediação, 1998.

Trajetórias das concepções de educação infantil. São Paulo, 2004. Disponível em: < http://www.omep.org.br/ artigos/palestras/05.pdf $>$. Acesso em: 10 out. 2004 
ROCHA, H. P. Educação escolar e higienização da infância. Caderno Cedes, Campinas, v. 23 , n. 59 , p. 39-56, abr. 2003.

SOUZA, J. F. Governando mulheres e crianças: jardins de infância em Porto Alegre na primeira metade do século XX. Tese (Doutorado em Educação) - Universidade Federal do Rio Grande do Sul, Porto Alegre, 2000.

UBERTI, L. Diário de um bebê: governo da subjetividade infantil. Dissertação (Mestrado em Educação) - Universidade Federal do Rio Grande do Sul, Porto Alegre, 2002.

VARELA, J.; URIA, F. A. A maquinaria escolar. Teoria \& Educação, Porto Alegre, n. 6, p. 68-96, jan./jul. 1992.

. O estatuto do saber pedagógico. In: SILVA, T. T. (Org.). O sujeito da educação: estudos foucaultianos. Petrópolis: Vozes, 1994.

Categorias espaço-temporais e socialização escolar: do individualismo ao narcisismo. In: COSTA, M. V. Escola básica na virada do século: cultura, política e currículo. São Paulo: Cortez, 1996.

VEIGA-NETO, A. Pensar a escola como uma instituição que pelo menos garanta a manutenção das conquistas fundamentais da Modernidade. In: VORRABER, M. C. (Org.). A escola tem futuro? Rio de Janeiro: DP\&A, 2003.

YALOM, M. O seio político: seios para a nação. In:

História do seio. Lisboa: Teorema, 1988.

Encaminhado em: 03/07/06

Aceito em: 28/09/06 